BMA, London, UK

Sheather@bma.org.uk

Cite this as: $B M J 2021 ; 372: n 28$

http://dx.doi.org/10.1136/bmj.n28

Published: 08 January 2021

\section{Covid-19 has amplified moral distress in medicine}

\author{
Simply working harder cannot resolve the conflicts caused by responsibility without autonomy \\ Julian Sheather, Helen Fidler
}

Doctors are accustomed to difficulty, to long hours, high stress, heavy responsibility. The job involves helping people navigate life's gravest challenges: death and dying, suffering, loss, and grief. It can regularly require tough life-altering decisions in the face of uncertainty. Such challenges are far from trivial. For as long as there have been healers though, this has been part of the territory.

Challenges well met can also bring rewards-they are linked to the satisfactions of medicine. But as the profession draws deeply on its resources to respond to covid-19, a new concept is entering the mainstream: moral distress. ${ }^{12}$ And it is shining a light on the deepening structural afflictions of medicine in the UK, problems that predated covid and, unless they are resolved, will endure long beyond it.

Moral distress is a psychological harm arising when people are forced to make, or witness, decisions or actions that contradict their core moral values. While exposure to the suffering of others can lead to distress, it is not necessarily moral distress. But if serious and sustained resource constraints mean doctors cannot meet patients' needs, it can open the door to moral distress. If you know that delays to treatment will likely lead to serious harms, consider the effect of repeatedly being forced to place patients on ever lengthening waiting lists. Moral distress arises in the gap between what professional judgment dictates should be done and what healthcare systems permit. It is also associated with powerlessness-the impossibility of altering the situation so that professional acts can accord with professional values.

Understandably, moral distress has been strongly linked to the psychological harms of combat. ${ }^{3}$ The term entered health through nursing ethics ${ }^{4}$ : lack of professional agency meant that nurses felt unable to challenge behaviour at odds with their core values. It found traction among health professionals working in humanitarian crises, where professional norms have at times been profoundly challenged. Typical emotional responses to moral distress include feelings of guilt, shame, anger, and, in extreme form, disgust. ${ }^{5}$ If moral distress is sustained it can lead to moral injury-a deeper or more enduring harm that can lead to burnout and psychological trauma.

The term moral distress is increasingly used to describe the cumulative unease experienced by doctors struggling to fulfil their primary professional obligations in once highly resourced medical settings. During the covid pandemic, situations strongly linked to moral distress include the rationing or triaging of scarce resources such as ventilatory support, intensive care beds, or protective equipment; de-prioritising patients who have substantial non-covid related health needs and who are likely to be harmed by treatment delays; being barred from work by covid rules when colleagues and patients desperately need help; making harrowing ethical choices without appropriate support; denying patients access to vital social and emotional support because of infection control requirements. The list goes on.

\section{Damage from underfunding}

It will be said that covid is exceptional. That every health system in the world is struggling. That there will be a reset. But covid is exacerbating existing pressures rather than creating new ones. The slow tightening of the garotte of underfunding has created ideal conditions for moral distress, sapping the joy from the doctor-patient relationship, depleting the rewards of clinical medicine, swapping pleasure for grinding distress. Plenty of anecdotal evidence suggests it contributes to early retirement among senior medical staff and to a general crisis of retention in medicine more broadly.

The NHS needs to be properly resourced. We must not allow permanent underfunding to place health professionals in unending ethical conflict. In the meantime, doctors must learn to recognise their own moral distress, identify its sources, and understand that they are not at fault. Open discussion and peer support are essential, acknowledging that simply working harder cannot resolve the conflicts born from responsibility without autonomy. Schwartz rounds ${ }^{6}$ can play a vital role here, but only if doctors have time to attend. Doctors must also be supported when making challenging ethical decisions, including ensuring access to ethical and legal expertise. Doctors must be psychologically-and

contractually-permitted to make time for reflection and self-care. They cannot run on fumes indefinitely.

Revolutions are said to eat their children. Tragically, the same is true of dysfunctional organisations. They force virtuous employees into intolerable positions as professional codes collide with institutional diktat often rooted in resource constraints. Covid has highlighted how essential the NHS is to our collective wellbeing. It is beyond time to fund it effectively-and to make clear the costs of not doing so. Until then, all health professionals need support in managing moral distress-before its effects become too toxic.

Competing interests: We have read and understood BMJ policy on declaration of interests and have no interests to declare.

Provenance and peer review: Not commissioned; not externally peer reviewed.

Houston S, Casanova MA, Leveille M, etal. The intensity and frequency of moral distress among different healthcare disciplines. J Clin Ethics 2013;24:98-112.pmid: 23923809 
2 Greenberg N, Docherty M, Gnanapragasam S, Wessely S. Managing mental health challenges faced by healthcare workers during covid-19 pandemic. BMJ 2020;368:m1211.

doi: 10.1136/bmi.m1211 pmid: 32217624

3 Syracuse University. What is moral injury? The Syracuse University moral injury project. https://moralinjuryproject.syr.edu/about-moral-injury/

4 Jameton A. Nursing practice: The ethical issues. Prentice Hall, 1984.

5 US Department of Veterans Affairs. Moral injury. https://www.ptsd.va.gov/professional/treat/cooccurring/moralinjury.asp

6 Point of Care Foundation. Schwarz rounds. https://www.pointofcarefoundation.org.uk/ourwork/schwartz-rounds/about-schwartz-rounds/

This article is made freely available for use in accordance with BMJ's website terms and conditions for the duration of the covid-19 pandemic or until otherwise determined by BMJ. You may use, download and print the article for any lawful, non-commercial purpose (including text and data mining) provided that all copyright notices and trade marks are retained. 